
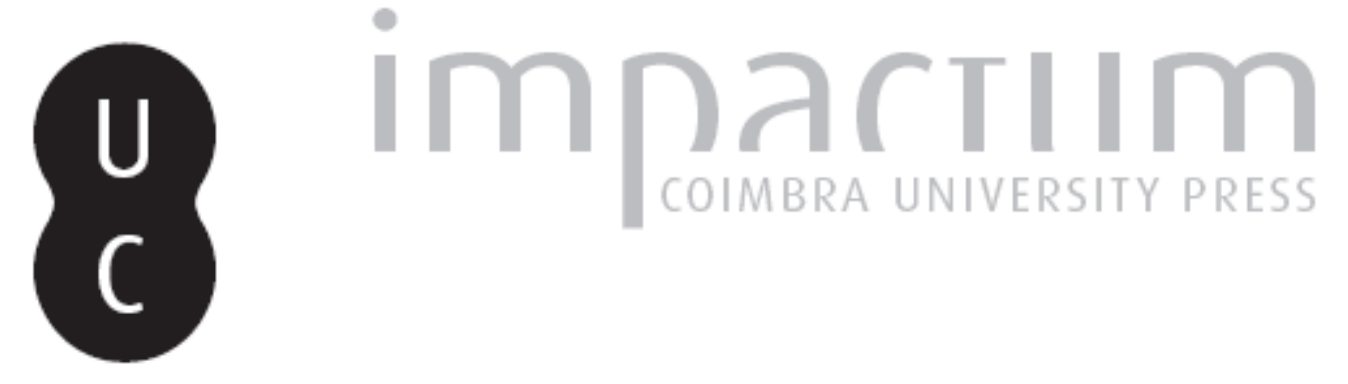

\title{
A habitação como uma das componentes da qualidade do ambinete urbano: o caso do Porto e arredores
}

Autor(es): $\quad$ Matos, Fátima Loureiro de

Publicado por: Associação Portuguesa de Riscos, Prevenção e Segurança

URL persistente:

URI:http://hdl.handle.net/10316.2/40144

DOI:

DOI:https://doi.org/10.14195/1647-7723_4_3

Accessed : $\quad$ 26-Apr-2023 13:35:50

A navegação consulta e descarregamento dos títulos inseridos nas Bibliotecas Digitais UC Digitalis, UC Pombalina e UC Impactum, pressupõem a aceitação plena e sem reservas dos Termos e Condições de Uso destas Bibliotecas Digitais, disponíveis em https://digitalis.uc.pt/pt-pt/termos.

Conforme exposto nos referidos Termos e Condições de Uso, o descarregamento de títulos de acesso restrito requer uma licença válida de autorização devendo o utilizador aceder ao(s) documento(s) a partir de um endereço de IP da instituição detentora da supramencionada licença.

Ao utilizador é apenas permitido o descarregamento para uso pessoal, pelo que o emprego do(s) título(s) descarregado(s) para outro fim, designadamente comercial, carece de autorização do respetivo autor ou editor da obra.

Na medida em que todas as obras da UC Digitalis se encontram protegidas pelo Código do Direito de Autor e Direitos Conexos e demais legislação aplicável, toda a cópia, parcial ou total, deste documento, nos casos em que é legalmente admitida, deverá conter ou fazer-se acompanhar por este aviso.

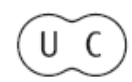




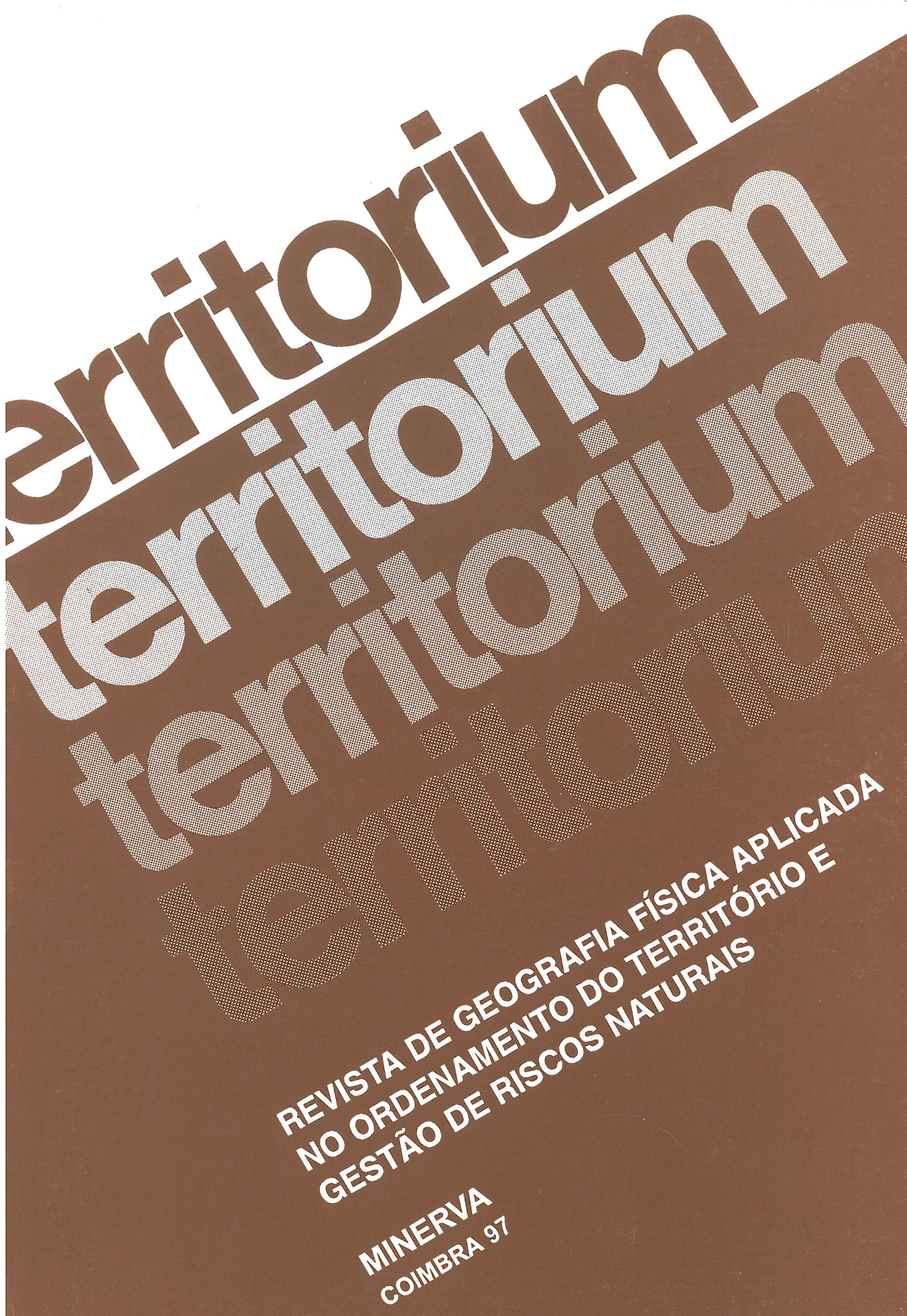




\title{
A habitação como uma das componentes da qualidade do ambinete urbano. O caso do Porto e arredores
}

\author{
Fátima Loureiro de Matos*
}

\section{Resumo:}

Neste artigo analisa-se a importância da qualidade da habitação no quadro da qualidade do ambiente urbano. Há hoje muitos problemas nas áreas urbanas: excesso de locatários por habitação, falta de conforto, habitações degradadas, bairros de barracas e alojamentos sem condições mínimas, por exemplo, no que respeita a instalações sanitárias, água e esgotos. Todavia, a questão da qualidade da habitação não é unicamente uma consequência da crise dos alojamentos, mas é preciso olhar também atentamente os espaços públicos, sobretudo os espaços verdes e os de prática de desportos.

Faz-se igualmente referência às ligações, no meio dos mal-alojados, entre agravamento do estado de saúde (asma, reumatismo, etc.), pobreza, desemprego de longa duração e aumento de problemas de comportamento (alcoolismo, droga, violência, criminalidade).

Nos últimos anos, os poderes públicos fizeram esforços para melhorar esta situação com a promoção de espaços verdes, parques desportivos e de lazer, assistência social aos casais, à população idosa e às crianças, reabilitação de habitaçōes antigas e construção de novos alojamentos sociais.

Palavras chave:

Ambiente urbano, habitação, Porto.

\section{Résumé:}

Dans cet article nous analysons l'importance de la qualité de l'habitation dans le cadre de la qualité de l'environnement urbain. La question de la qualité de l'habitation est, en grande partie, le résultat du déficit de logements. Aujourd'hui, il y a beaucoup de problèmes dans les régions urbaines: surpeuplement des logements, inconfort, habitations degradées, bidonvilles et logements sans conditions minimes d'habitabilité, par exemple, installations sanitaires, eau, égouts. Toutefois, la question de la qualité de l'habitation n'est pas uniquement une conséquence de la crise du logement; il faut aussi regarder attentivement les espaces publics, surtout espaces verts et espaces pour la pratique du sport.

Cet article fait aussi référence aux liaisons, parmi les mal-logés, entre aggravation de l'état de santé (asthme, rhumatisme, etc.), pauvreté, chômage de longue durée et montée des troubles du comportement (alcoolisme, drogue, violence, criminalité). Ces dernières années, les pouvoirs publics ont fait des efforts pour améliorer cette situation avec la promotion des espaces verts, des parcs sportifs et de loisir, l'assistence sociale aux ménages, à la population âgée et aux enfants, la réhabilitation des habitations anciennes et la construction de nouveaux logements sociaux.

Mots clés:

Environnement urbain, habitation, Porto.

\section{Abstract:}

In this paper we analyse the significance of housing quality in the context of urban environment quality. The research theme of housing quality results, mainly, from the housing deficit. This deficit is essencially due to the aggravation of cohabitation situations, following the increase number of shanties and other low income housing, without the least conditions of life, like water supply and drain and also from the significant number of old houses. However, housing quality is not only dependent on the quality of the house, we must also take into account the existence of green spaces and other spaces of leisure and sports.

This paper also shows the strong correlation between inadequate housing, health problems (asthma, rheumatism, and so on), poverty and social disorder (alcohol and drugs, violence, crime). In the last years the Local Authorities and the Government have increased their concern over these problems and developed some iniciatives: new green spaces, new leisure and sport spaces, family income supplements, social work, including young children, adolescents and elderly assistence and care, housing rehabilitation and new social housing.

Key words:

Urban environment, housing, Oporto.

* Instituto de Geografia. Faculdade de Letras. Universidade do Porto. 


\section{Introdução}

A habitaçãoé sem dúvida uma necessidade básica, uma vezque todos almejamos um alojamento condigno; trata-se, aliás, de um dos direitos consagrados na Constituição da República, ou se quisermos alargar o espaço de referência, um direito reconhecido internacionalmente ${ }^{(1)}$.

Sendo esta a característica mais geral, porque a mais comum, a perspectiva que adoptamos, como o primeiro e principal ponto de referência, é a centrada nas famílias e nas suas condições habitacionais.

Contudo, habitação é muito mais do que isto, ela é o resultado de um processo produtivo que envolve um conjunto de actores: promotores, empresas de construção, compradores, inquilinos, senhorios, financiadores, mediadores, etc.

É, também um elemento, porventura o de maior impacto devido ao espaço que ocupa, da estrutura e imagem do território, particularmente das áreas urbanas, permitindo-nos então considerar outra perspectiva de análise, ao interrogarmo-nos acerca da forma como se constrói, como se vive, incluindo aqui as relações entre casa e trabalho, entre a casa e os espaços de consumo, perspectiva esta que dará mais ênfase às questões da qualidade habitacional e do ambiente urbano.

Habitaçãoé, ainda, um património, uma forma de investimento e de captação de poupanças, o que implica questionarmo-nos sobre as condições de investimento, o significado que a propriedade assume no rendimento, nas estratégias e na diferenciação das famílias.

Além destas perspectivas de análise até ao momento enunciadas, não podemos deixar de referir o seu papel nas "políticas sociais", particularmente as que se associam aos chamados "Estados-Providência", podendo então estudar-se a habitação como questão das políticas sociais e urbanas.

Todas estas vertentes de análise encontram-se interligadas, sendo difícil fazer um estudo isolado de cada uma delas; na verdade, para haver habitação é preciso solo, investimento, trabalho, possibilidades de acesso e capacidade de manter, ao longo do tempo, as condições de habitação. Daí que a compreensão dos processos e a discussão do que se pode fazer não sejam alheias à preocupação pela forma como estes processos, de investimento, de distribuição e de gestão, se relacionam, sendo estas relações fundamentais para percebermos os problemas habitacionais.

(1) Refiram-se, entre outras, algumas das iniciativas levadas a cabo pelas Naçōes Unidas, nestes últimos anos, em que se chama a atenção para a melhoria da qualidade de vida das populações, particularmente as dos países do Terceiro Mundo, salientando-se a questão da habitação: I ${ }^{\mathrm{a}}$ Conferência sobre os Povoamentos Humanos (Habitat I - Vancouver 1976); Ano Internacional dos Sem Abrigo (1987); Conferência Habitat II (1996 - Istambul).
Uma das características chave da habitação é a sua durabilidade e imobilidade, assim, o tempo é um factor importante na análise, porque o presente é fruto tanto dos investimentos passados, como das expectativas futuras. Além do tempo, o espaço é fundamental, particularmente ao nível da escala. O sistema habitacional é coerente a diferentes escalas - o quarteirão, o bairro, a cidade, a região, o país.

Analisar e avaliar as condições habitacionais das famílias nãoé tão simples como à partida poderiamos pensar, pois o significado da habitação varia de época para época com os diferentes grupos sociais, para além de que a habitação envolve múltiplas dimensões difíceis de traduzir num único indicador.

Estar alojado é muito mais do que estar numa casa, esta tem de possuir determinadas características (conforto, espaço suficiente para a família, equipamentos, distância aos serviços públicos/privados, aos diferentes tipos de comércio e a outras actividades complementares à habitação, como por exemplo as de lazer)e, ao mesmo tempo, implica certas condições, como as despesas de manutenção da casa e dos seus espaços envolventes.

Estas ideias podemos incluí-las naquilo a que muitos autores referem como "qualidade habitacional", que constitui, aliás, uma das componentes da "qualidade do ambiente urbano".

O conceito de qualidade habitacional é complexo porque não é absoluto, nem estático, pelo contrário, é relativo, pois varia de país para país, com os diferentes grupos sociais e com o tempo. A existência de más condições habitacionais não pode ser considerada, apenas, como um problema arquitectónico ou técnico; é fundamentalmente um problemaeconómicoe político.

Para compreendermos a dimensão desta questão, da qualidade habitacional, podemos observar o esquema apresentado na fig 1 , onde os dois pontos chave são, precisamente, a disponibilidade de alojamentos e o seu preço.

As relações que a figura nos mostra não são recentes; elas foram já identificadas no séc. XIX, por Edwin Chadwick no seu trabalho intitulado "Report on the Sanitary Condition of the Labouring Population of Great Britain'(2), publicado em 1842. Neste relatório, o Autor verificou que a disponibilidade e o preço dos alojamentos estão intimamente relacionados com a sua qualidade, incluindo as condições de ocupação, além de salientar a existência de uma forte correlação entre as taxas de mortalidade da população urbana e as condições económicas e habitacionais das famílias. Aspectos como estes são, aliás, também referidos para a cidade do Porto, nos estudos efectuados pela Escola Médico-Cirúrgica do Porto, nos finais do

(2) Citado em Roderick J. LAWRENCE - "Housing Quality Research", Urban Studies, Vol. 32(10), Dez. 1995, p. 1658-59. 


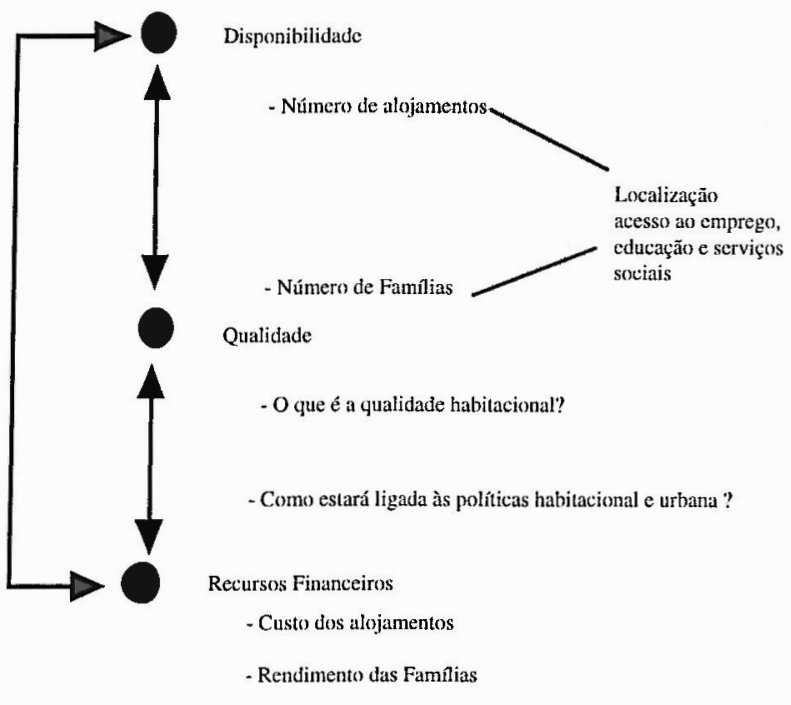

Fonte: Adaptado de Roderick J. LAWRENCE (1995)

Fig. 1 - Perspectiva integrada dos estudos de qualidade habitacional

séc XIX, particularmente nos trabalhos de Ricardo Jorge ${ }^{(3)}$, em que, precisamente, se descrevem as péssimas condições habitacionais em que vivia a população operária do Porto, residente quer nos alojamentos superlotados do centro histórico ${ }^{(4)}$, e "casas de malta"(5) (dos Bairros da Sé, Barredo e Ribeira), quer nas "ilhas" ${ }^{(6)}$, onde proliferavam várias doenças infectocontagiosas, como a sífilis, a varíola, a difteria, as febres tifóides e a tuberculose, ${ }^{(7)}$ possuindo estas áreas altíssimas taxas de mortalidade.

(3) Entre outros, saliente-se - Demographia e Hygiene da Cidade do Porto. Porto, Repartiçăo de Saúde e Hygiene da Câmara Municipal do Porto, 1899.

(4) Em que as casas eram arrendadas aos andares e aos quartos, onde vivia uma população proletária em condições subhumanas.

(5) Tratava-se de um tipo de alojamento preferencialmente ocupado pela população masculina que vinha trabalhar para a cidade durante a semana, voltando para as suas aldeias ao fim de semana. " (...) Os codeas, serventes de pedreiros, que ganham miserávelmente o seu sustento, arrancham em casas de malta, aos dez e aos doze na mesma imunda sala, estendidos em taboas collocadas em toscas travessas de pinheiro, sem sobrado(...) " - O "Século", n' 6321 de Agosto de 1899, cit. por Caeiro da Matta Habitações Populares. Coimbra, Estudos Económicos e Financeiros, Imprensa da Universidade, 1909, p.66.

(6) Na sua forma mais simples, as ithas consistiam em filas de pequenas casas de um só piso, construídas nos quintais das habitações da classe média, com acesso à rua através de um estreito corredor sob estas habitações burguesas construídas à face da rua.

(7) As péssimas condições de salubridade destas áreas toruou-as marginais, sendo associadas à perdição e ao crime, onde até as autoridades tinham medo de penetrar, como se depreende da leitura de notícias da época: Inquérito da Imprensa à Miséria do Porto, de 1885; Gervásio Lobato Os Mistérios do Porto, 1893, citados por Gaspar Martins Pereira- Famílias Portuenses na Viragem do Século (1880-1910). Porto, Afrontamento, 1995, p.64. Situação não muito diferente, infelizmente, do que acontece actualmente, bastando ler as notícias publicadas na Imprensa, por exemplo - O Atlas do Portugal Perigoso, "Jornal O Público", 19/06/1994.
O interesse pelas questões relativas à qualidade de vida das áreas urbanas tem vindo a crescer nos últimos anos; vejam-se os documentos publicados pela União Europeia, como por exemplo, o "Greenbook on the Urban Environment", de 1990, ou pela OCDE, o seu relatório sobre "Environmental Policies for Cities in the 1990's". A partir dos finais dos anos 80 , surge uma variedade de novos conceitos, como os de "green city", "eco-city", "liveable city", "resourceful city", "environmental city" e o de "sustainable city".

$O$ conceito de sustentabilidade foi descrito no chamado "Brundtland Report - Our Common Future", de 1987. Em termos gerais pode ser definido da seguinte forma: o desenvolvimento sustentável existe quando a geração presente consegue satisfazer as suas necessidades sem comprometer a satisfação das necessidades futuras das próximas gerações. Em termos habitacionais, isto quer dizer que as respostas que forem dadas hoje para resolver os problemas habitacionais das nossas cidades não podem comprometer o futuro, sobretudo no respeitante à ocupação desregrada do solo com construções sem a mínima qualidade.

A questão da qualidade habitacional resulta, em grande parte, do défice de alojamentos existentes, particularmente nas áreas metropolitanas, e que leva à existência de alojamentos sobreocupados, alojamentos improvisados (barracas e outros), alojamentos sem instalações sanitárias e equipamentos básicos (água, luz, esgotos), alojamentos degradados, muitas vezes em situação de ruína mas que se mantêm ocupados, pondo em risco a vida dos seus ocupantes, como acontece nas freguesias mais antigas, quer da cidade, quer dos concelhos periféricos.

Assim, os aspectos ligados ao conforto da habitação, ao seu estado de conservação, bem como, ao esforço dispendido pelas famílias na sua apropriação/manutenção, são importantes para compreendermos a dimensão das carências existentes, embora de difícil quantificação com os indicadores de que dispomos.

\section{Características gerais da habitação - Quali- dade dos edifícios habitacionais, dos espaços envolventes e de apoio à habitação}

Ligada à questão da qualidade habitacional, têm vindo a desenvolver-se, nos últimos anos, vários estudos no campo médico, particularmente na área da epidemiologia, psicologia e psiquiatria, acerca do chamado "sindroma dos edifícios doentes" ${ }^{\text {"(8) }}$, chamando

(8) Saliente-se entre outros: R. BURRIDGE ; D. ORMANDY - Unhealthy Housing: Research, remedies and Reform. London, E.\& F.N. Spon, 1993; B. INEICHEN - Homes and Health: how Housing and Health Interact. London, E.\&F.N. Spon, 1993 (citado em Roderick J. LAWRENCE (1995, p. 1663) 
a atençãopara o desenvol vimento de certas patologias ${ }^{(9)}$ ligadas às más condições de construção dos edifícios habitacionais, como é o caso das questões ligadas à má drenagem dos terrenos, à emissão de gases, ao uso de materiais tóxicos, à ventilação inadequada dos edifícios e ao inadequado isolamento térmico promovendo o aparecimento de humidades.

As questões referidas fazem aumentar o número dos alojamentos deficientes, ou seja, aqueles que seria necessário substituir, para se proporcionar uma melhoria da qualidade de vida às famílias a residir nestas condições.

Mas, a qualidade habitacional não depende, unicamente, da qualidade do alojamento em si, já que não podemos esquecer, também, os aspectos que se prendem com os espaços envolventes, sendo fundamental a existência de espaços verdes e para a prática de lazer.

Outro aspecto que não podemos deixar de salientar, é o facto de as áreas de fraca qualidade habitacional coincidirem com as áreas de concentração da população mais carenciada economicamente, como a população idosa, com pequenas reformas, desempregados de longa duração, população com empregos precários e mal remunerados ${ }^{(10)}$, portanto, uma população fragilizada em termos económicos, que não consegue aceder a habitações condignas, aumentando, também, o número dos sem abrigo. Aliás, este fenómeno parece estar a alastrar nos países Europeus, particularmente nas grandes cidades (Paris, Madrid, Londres, Lisboa, Porto......). ${ }^{(11)}$

Um dos factores responsáveis pela chamada "crise das cidades" é, na verdade, a questão da chamada "crise habitacional", a qual se manifesta:

- num défice habitacional - saliente-se que na Área Metropolitana do Porto (A.M.P.), em 1991, faltavam cerca de 22000 fogos;

- na sobreocupação dos alojamentos existentes, sendo comum a coabitação entre duas ou mais famílias que partilham o mesmo alojamento - na A.M.P. encontravam-se, segundo o Censo de 1991, 22224 famílias nesta situação (pouco mais de $6 \%$ das famílias, valor que está acima da média do Continente e da Região Norte), existindo ainda 107150 famílias em alojamentos considerados superlotados, segundo os critérios definidos pelo INE, situação aliás bastante pior do que a existente em 1981 e que afecta cerca de 1/3 das famílias da AMP, valor que está, igualmente

(9) Săo exemplos a asma, as alergias respiratórias e cutâneas, o cancro e a "Multiple Chemical Sensitivity" (Sindroma de Alergia Múltipla), doença já diagnosticada nos Estados Unidos, mas de que em Portugal ainda não se conhecem casos.

(10) Muitos destes na esfera da chamada "economia informal".

(11) Salientem-se, entre outros, os seguintes trabalhos: A. GREEN (1994); Alan McGREGOR; Margaret McCONNACHIE (1995, p. 1587-1600); Comissão Europeia (1993, p. 3-27). acima da média do Continente e da Região Norte. $\mathrm{O}$ aumento das situações de sobreocupação é uma tendência muito significativa e, do ponto de vista da qualidade habitacional, preocupante;

- na existência de alojamentos improvisados barracas e outros alojamentos precários - na A.M.P., em 1991 existiam cerca de 2000 alojamentos deste tipo, nos quais viviam mais de 7500 pessoas.

Esta situação de carência habitacional é em parte resultante, por um lado, do rápido acréscimo populacional, por outro, das grandes transformações económicas e sociais ocorridas nas grandes cidades, ou ainda, dos custos especulativos dos alojamentos, quer para arrendamento, quer para compra e, por último, da fraca construção de habitação social, havendo, por isso, uma percentagem significativa da população que não tem acesso aos alojamentos que se encontram no mercado.

Uma das consequêncais deste défice é a existência de áreas de habitação degradada e desordenada, sem as condições mínimas de habitabilidade, onde vivem geralmente populações em situações de exclusão social e pobreza.

É também nestas áreas que nos últimos anos se vem assistindo ao aumento da criminalidade, toxicodependência, alcoolismo e delinquência juvenil, associada à carência de emprego, pobreza e desestruturaçãa familiar.

A construção clandestina surgiu, nos anos 60-70, como uma resposta à incapacidade do mercado formal em assegurar as necessidades de habitação de um largo segmento da população recém-urbanizada e pouco solvente. Esta forma de crescimento urbano gerou graves problemas, principalmente nas periferias das grandes cidades, como o sub-equipamento e a falta de infraestruturas, criando áreas de fraca qualidade habitacional, nas quais é necessário intervir para proporcionar à população que nelas vive a qualidade de vida a que tem direito.

A degradação dos edifícios habitacionais e as más condições de salubridade e higiene é, com efeito, preocupante nos dias de hoje em muitas áreas da cidade - como, por exemplo, nas ilhas, nos bairros de barracas que ainda existem, nas áreas residenciais mais antigas, apesar do esforço que tem sido desenvolvido pelas autarquias e governo para a sua erradicação e recuperação.

Quer as ilhas, quer as casas mais antigas, sobretudo as que se encontram arrendadas, não oferecem 0 mínimo de condições de habitabilidade, encontrando-se algumas em situação de ruína eminente, não dispõem, por vezes, de instalações sanitárias, nem abastecimento de água. Para além disso, não possuem um adequado arejamento, nem luminosidade, devido à falta de janelas ou ao seu pequeno tamanho, faltando também um adequado isolamento acústico e térmico, 
devido ao material barato utilizado na sua construção e inexistência de obras de manutenção, dadas as baixas rendas praticadas. Estes aspectos, contribuem para a proliferação de doenças, como o reaparecimento de casos de tuberculose, asmas, bronquites, reumatismo crónico, entre outras.

São várias as artérias da cidade onde se sucedem vários prédios abandonados, qual barcos naufragados, em ruínas há vários anos, com portas e janelas arrombadas, sacadas e varandas destruídas, telhados esburacados, onde por vezes se abrigam à noite, populações marginais, como os sem abrigo e os toxicodependentes, conferindo uma imagem desagradável e desoladora, àqueles que por elas circulam.

Aliada a esta questão da qualidade habitacional, encontra-se a falta de espaços ao ar livre (jardins, parques infantis e desportivos) que possam ser usufruídos pelos moradores, sobretudo pela população idosa, pelos jovens e crianças.

Quando estes existem, encontram-se muitas vezes mal cuidados, em parte devido ao facto da população não estar adequadamente educada para a sua preservação e manutenção.

As autarquias têm vindo a desenvolver esforços no sentido de procurar melhorar esta imagem ${ }^{(12)}$, investindo no ajardinamento dos espaços envolventes aos bairros sociais e na construção de espaços verdes, para desporto e lazer ${ }^{(13)}$.

Contudo, há que pensar na forma de os gerir envolvendo as populações locais, através da criação de comissões de bairros ou das colectividades locais, como os clubes e associações, como aliás tem sido implementado por algumas Câmaras.

Saliente-se, ainda, que muitos bairros novos periféricos apesar de oferecerem condições de alojamento razoáveis, propiciam uma baixaqualidade de vida. A imaginação dos promotores e a especulação levaram à construção de alguns conjuntos desarticulados e sem qualidade, em que existe uma anulação completa

(12) De acordo com o Conselho da Europa, o ideal numa cidade é a existência de quatro metros quadrados de superfície por habitante, repartidos pelas tipologias consideradas como equipamentos de base, sendo reservados $96 \%$ dessa área para actividades desportivas ao ar livre, $2,5 \%$ para salas de desporto e pavilhões e $1,5 \%$ para piscinas ao ar livre e cobertas.

(13) Refiram-se, entre outras, algumas das iniciativas levadas a cabo pela autarquia do Porto: Parque da Cidade; Complexo Desportivo do Monte Aventino; Parque de S. Roque; Centro Desportivo da Pasteleira, que incluí um campo de futebol, campo de jogos polivalente, estruturas de apoio e ainda piscinas cobertas, situado junto ao Bairro social; Parque Urbano da Mata da Pasteleira, que irá ocupar a área onde existia um bairro de barracas que entretanto foi demolido; Centro Desportivo de Campanhã, em construção, que inclui um complexo de piscinas, campo de jogos e estruturas de apoio; vários pavi hoōes gimnodesportivos, quer pertencentes a escolas do ensino básico e secundário, quer mesmo ao ensino superior, que servem não só para a prática gimnodesportiva escolar como também seencontram abertos a iniciativas de pequenos clubes desportivos existentes nas várias freguesias da cidade. A Câmara tem ainda apoiado a construção e renovação de muitos equipamentos desportivos de clubes e associaçס̄es da cidade. dos elementos tradicionais da estrutura urbana - as ruas, as praças e os jardins.

Até aqui salientamos os aspectos negativos de algumas áreas habitacionais, contudo, existem também áreas de grande qualidade, promovidas quer por investidores privados, quer pelas autarquias ou ainda pelas cooperativas de habitação.

Estas áreas de qualidade correspondem a áreas ocupadas pela população mais rica, onde predomina a habitação unifamiliar, ao longo de arruamentos geralmente arborizados, como por exemplo, as áreas da Foz, Marechal Gomes da Costa, Antas, Guerra Junqueiro, Leça, Miramar, Granja ou ainda os novos modelos habitacionais de luxo - como é o caso do aparecimento de empreendimentos de luxo, quase todos com nome próprio, bem como os condomínios fechados, estes últimos, considerados como o modelo acabado da segregação social, na medida em que são espaços fechados usufruídos apenas por um certo grupo social ${ }^{(14)}$. Além destas áreas de qualidade habitacional, outras surgem onde se tem instalado uma população média-baixa, caso por exemplo de algumas urbanizações construídas por cooperativas ${ }^{(15)}$, dos bairros de casas económicas, predominantemente unifamiliares ${ }^{(16)}$ construídos pelo Estado Novo, ou ainda, os recentes bairros municipais de média dimensão. Estes últimos apresentam uma razoável qualidade arquitectónica dos edifícios, com uma integração entre a função habitacional e os espaços verdes e de lazer, possuindo ainda, áreas destinadas ao comércio e serviços de apoio à habitação como, por exemplo, o Bairro de Santa Luzia, na cidade do Porto.

\section{Algumas intervenções e projectos já realizados e/ou em curso para melhorar a qualidade habitacional}

As iniciativas desencadeadas pelo Estado, no âmbito do combate à exclusão social, têm incidido precisamente nestas áreas de habitação degradadas procurando melhorar as condições habitacionais através de programas de construção de habitação social e, ainda, através de projectos de requalificação destes

(14) Estas novas formas de habitar têm vindo a surgir não só nas duas Áreas Metropolitanas (Porto e Lisboa) mas, também, em espaços de turismo, como o Algarve ou mesmo no Litoral Norte (caso de Esposende, por exemplo).

(15) Salientem-se, entre outras, a urbanização da Cooperativa Mãos-à-Obra em Rio Tinto, as urbanizações da Barranha e Azenha de Cima, na Sra da Hora, promovidas pela Cooperativa Sete Bicas e a urbanização da Nortecoope, na Maia.

(16) Nos últimos anos têm sido vendidas muitas destas habitações, depois de recuperadas e até ampliadas conferindo-lhes uma melhoria substancial tanto no seu arranjo interior como exterior, alterando-se quase sempre o projecto inicial, o que tem contribuido para um aumento significativo do seu valor no mercado habitacional. 
espaços, de apoio económico às famílias, quer também de qualificação profisssional.

Contudo, apesar do esforço que o Estado e as autarquias têm vindo a desenvolver nesta área, ou seja, na melhoria das condições habitacionais de uma parte significativa da população, nem sempre os resultados têm sido os melhores, porque esse realojamento não tem sido acompanhado de medidas que permitam uma efectiva integração social dos realojados, continuando estes, numa situação de exclusão.

Esta situação, que se tem agravado nos últimos anos, está geralmente ligada à expansão de graves problemas sociais, como a insegurança, a violência, a criminalidade, o racismo, a xenofobia, a delinquência e o tráfico de droga, que afectam, particularmente, os bairros sociais, as âreas degradadas das grandes cidades e as áreas desqualificadas suburbanas, onde vive uma população jovem desenraízada, sem perspectivas, em conflito com a escola e com o mercado de emprego.

Estes fenómenos têm sido apontados como o resultado de uma política urbana e de habitação social inadequada, que criou modelos e formas urbanas (os grandes blocos residenciais em urbanizações uniformes) que favoreceram a exclusão ao quebrarem as relações de vizinhança e de familiaridade, dificultando a integração e levando a uma crise dos valores morais e sociais.

As autarquias, juntamente com os vários governos e as cooperativas, têm desenvolvido um grande esforço na melhoria da qualidade habitacional, através de alguns projectos, nomeadamente:

- o Plano de Melhoramentos da cidade do Porto - grande intervenção urbanística que se iniciou em 1956 , prolongando-se até 1974 , cujo objectivo era a destruição das ilhas, sendo construídos 22 bairros camarários;

- o $S A A L^{(17)}$ - movimento que surge após o 25 de Abril, na sequência de várias manifestações das populações mal alojadas, sendo extinto em 1976. Introduziu aspectos totalmente inovadores, ao envolver as populações das áreas mais degradas na resolução dos seus problemas habitacionais através da criação de comissões de moradores. No caso do Porto, as acções desenvolvidas levaram à recuperação de algumas ilhas na área de $S$. Victor e na Lapa, sendo a mais conhecida a da Águas Férreas, com projecto de Siza Vieira, mas também à construção de alguns bairros por comissões de moradores e à constituição de algumas cooperativas nas várias freguesias da cidade. Nos concelhos limítrofes a intervenção fez-se sentir sobretudo em áreas degradadas, como por exemplo em MatosinhoseemS.Pedroda Cova, concelhode Gondomar;
- o movimento cooperativo, que se expandiu depois do 25 de Abril, tem proporcionado o acesso a alojamentos de qualidade às populações de rendimentos médios;

- as operações integradas de recuperação/reabilitação, que visam a recuperação dos centros históricos e apoio às populações mais carenciadas que vivem nestas áreas, como por exemplo a Operação Ribeira - Barredo, no centro histórico da cidade do Porto;

- o RECRIA, projecto criado, pelo D.L. 4/88 de 14 de Janeiro, posteriormente modificado pelo D.L. 197/92, de 22 de Setembro, e pelo D.L. 104/96 de 31 de Julho, para apoiar os proprietários e as autarquias na recuperação de imóveis degradados;

- o REHABITA - criado pelo D.L. 105/96 de 31 de Julho, Regime de Apoio à Recuperação Habitacional em Áreas Urbanas Antigas, apenas aplicável aos núcleos históricos declarados áreas críticas de recuperação e reconversão urbanística;

- o RECRIPH - criado pelo D.L. 106/96 de 31 de Julho, tratando-se de um regime Especial de Comparticipação e Financiamento na Recuperação de Prédios Urbanos em Regime de Propriedade Horizontal;

- o PER - Programa Especial de Realojamento para as áreas metropolitanas de Lisboa e Porto, criado pelo D.L. 163/93, de 7 de Maio, com participação das autarquias e governo, que visa a erradicação dos bairros de barracas, das áreas de ilhas e outros casos de habitação degradada, e o realojamento destas famílias em alojamentos condignos, sejam bairros sociais ou outras soluções como, por exemplo, a compra de alojamentos usados ou novos pelas Câmaras Municipais, tendo sido esta uma das soluções adoptadas pelas autarquias de Gondomar e Matosinhos;

- o PCHE - Programa de Construção de Habitações Económicas, criado pelo D.L. 164/93 de 7 de Maio e alterado, posteriormente, pelo D.L. 181/94 de 29 de Junho, visando o financiamento à construção de habitações de custos controlados nas áreas metropolitanas de Lisboa e Porto;

- o URBAN - Programa Europeu para as áreas urbanas, cujo objectivoé a reabilitação e revitalização urbana de áreas degradadas do ponto de vista social e económico, por forma a promover a melhoria das condições de vida da população. Na Área Metropolitana do Porto, foram aprovados dois projectos deste tipo - o Urban do Vale de Campanhã, no concelho do Porto e o Urban de S. Pedro da Cova, no concelho de Gondomar;

- projectos de apoio às populações em risco-jovens, idosos, crianças, população feminina desempregada, jovens desempregados dos bairros sociais e áreas mais antigas, promovidos pelas Câmaras em conjunto com os Comissariados de Luta Contra a Pobreza e Instituições Particulares de Solidariedade Social; 
- o PROCOM (Programa de Apoio à Modernização do Comércio), que permite a melhoria da qualidade do ambiente urbano, melhorando sobretudo o conforto do consumidor através da criação de vias pedonais, com espaços dedicados ao descanso e ajardinamentos, alargamento de passeios e criação de parqueamento automóvel, revalorizando a sociabilidade ao permitir o redescobrir da relação passeio-montra-compra;

- recuperação de imóveis arquitectónicos com significado simbólico-emblemático na paisagem da cidade, que constituem elementos fundamentais do património das cidades, como uma das referências máximas na identificação das pessoas com o território que habitam e/ou que visitam.

\section{Conclusão}

A evolução dos conceitos de qualidade habitacional evoluíu ao longo deste século de forma rápida por força do processo de concentração urbana ocorrido em todo o mundo e particularmente na Europa, principalmente após a $2^{\mathrm{a}}$ Guerra Mundial, com a implementação de grandes programas de construção, que mobilizaram recursos e investimentos significativos.

Hoje, contudo, assiste-se à degradação e falência de muitos desses esforços e ao abandono dos modelos formais e conceptuais que significaram a ruptura com a cidade tradicional.

Em Portugal, o esforço do Estado e das autarquias na solução dos problemas da habitação, acompanhou de forma retardada o movimento europeu. A noção que se tem das políticas de habitação das últimas décadas é a de que a capacidade realizadora, quer pública, quer privada, ficou sempre aquém do avolumar dos problemas, particularmente os das Áreas Metropolitanas.

Outro aspecto a salientar é a questão da reabilitação do património existente, integrando a questão habitacional no âmbito mais vasto da reabilitação urbana." Recuperar centros tradicionais ou históricos, dotados de infraestruturas e equipamentos, com grande número de habitações degradadas... será por certo um programa de muito maior utilidade e eficácia social que continuar a expandir periferias sem carácter, para habitantes desenraízados da cidade que deviam integrar"(18).

Apesar das soluções adoptadas nem sempre terem sido as melhores para promover a qualidade habitacional, não podemos deixar de salientar o papel das cooperativas e dos novos programas, caso do PER e do PCHE.
São dezenas de milhar de fogos para construir, para cuja promoção há vontade política, meios organizativos estruturados e recursos financeiros. Torna-se necessário, contudo, ter cautela nas soluções a adoptar, tirando partido dos erros passados e procurando que estes não se repitam, para se poder, assim, revitalizar as cidades e criar ambientes urbanos em que a qualidade de vida adquira significado.

Uma nova política social de habitação e equipamento urbano deverá passar pelo abandono da ideia de que os programas habitacionais são questões autónomas, limitadas ao balanço entre o défice de alojamentos e a capacidade de os contruir.

Esta nova política deve conter novos modelos de "habitat" que se integrem na estrutura da cidade e contribuam para a consolidação dos sistemas urbanos em vez de os fragmentar, saliente-se, pela positiva, os que têm sido desenvolvidos por algumas cooperativas da A.M.P.. Deve igualmente apostar na recuperação e reabilitação dos bairros sociais existentes e das áreas históricas degradadas, responsabilizando as autarquias e os moradores na manutenção e tratamento do património construído, equipamentos de apoio à habitação e espaços verdes, para assim se conseguir uma melhoria da qualidade de vida e do ambiente urbano.

"Os programas apoiados ou promovidos pelas instituições públicas têm de ser conquistados para uma perspectiva integrada e actualizada sobre a qualidade da habitação, prolongando os aspectos positivos da experiência do passado recente e constituindo-se em referência exemplar para o mercado"(19).

\section{REFERÊNCIAS BIBLIOGRÁFICAS}

ASSOCIAÇÃO DOS ARQUITECTOS PORTUGUESES - Livro Branco da Arquitectura e do Ambiente Urbano em Portugal. Lisboa, Abril de 1996.

COMISSÃO EUROPEIA - "Towards a Europe of Solidarity: Combating Social Exclusion", Social Europe, sup. 4/93, 1993, p. 3-27.

GREEN, A. - The Geography of Poverty and Health. Institute for Employment Research, University of Warwick, 1994.

JORGE, Ricardo - Demographia e Hygiene da Cidade do Porto. Porto, Repartição de Saúde e Hygiene da Câmara Municipal do Porto, 1899.

JORNAL "O PÚBLICO" - O Atlas do Portugal Perigoso, 19 de Junho de 1994.

(19) Idem, Ib., p. 34. 
territorium $\quad 4.1997$

LAWRENCE, Roderick J. - "Housing Quality Research", Urban Studies, Vol. 32 (10), Dez. 1995, p. 1655-1664.

MATTA, Caeiro da - Habitações Populares. Coimbra, Estudos Económicos e Financeiros, Imprensa da Universidade, 1909.
MCGREGOR, Alan; MCCONNACHIE, Margaret - "Social Exclusion, Urban Regeneration and Economic Reintegration", Urban Studies, vol. 32(10), Dez. 1995, p. 1587-1600.

PEREIRA, Gaspar Martins - Famílias Portuenses na Viragem do Século (1880-1910). Porto, Afrontamento, 1995. 